NASA Technical Memorandum 83688

\title{
On-Orbit Cryogenic Fluid Transfer
}

John C. Aydelott

Lewis Research Center

Cleveland, Ohio

and

John P. Gille and Ralph N. Eberhardt

Martin Marietta Denver Aerospace

Denver, Colorado

Prepared for the

Twentieth Joint Propulsion Conference

cosponsored by the AIAA, SAE, and ASME

Cincinnati, Ohio, June 11-13, 1984

\section{N/Sก}




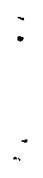




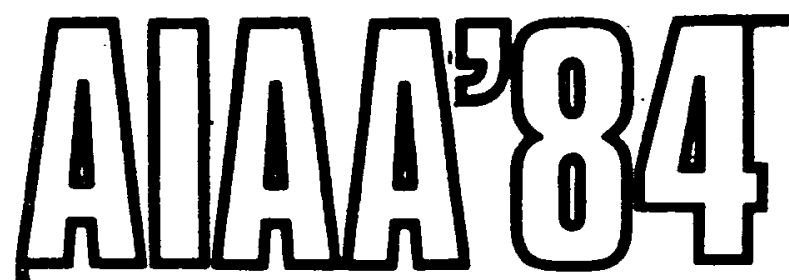

AIAA-84-1343

On-Orbit Cryogenic Fluid Transfer

John C. Aydelott, NASA Lewis Research

Center, Cleveland, $\mathrm{OH}$; and John P. Gille and Ralph N. Eberhardt, Martin Marietta Denver Aerospace, Denver, CO

\section{AIAA/SAE/ASME 20th Joint Propulsion Conference June 11-13, 1984/Cincinnati, Ohio}



ON-ORBIT CRYOGENIC FLUID TRANSFER

\author{
John C. Aydelott \\ National Aeronautics and Space Administration \\ Lewis Research Center \\ Cleveland, Ohio 44135
}

and

\author{
John P. Gille and Ralph N. Eberhardt \\ Martin Marietta Denver Aerospace \\ Denver, Colorado 80201
}

\section{Abstract}

A number of future NASA and DOD missions have been identified that will require, or could benefit g from resupply of cryogenic liquids in orbit. The $\sim$ most promising approach for accomplishing cryogenic i fluid transfer in the weightiess environment of space is to use the "thermodynamic" filling technique. This approach involves initially reducing the receiver tank temperature by using several charge-hold-vent cycles followed by filling of the tank without venting. Martin Marjetta Denver Aerospace, under contract to the NASA Lewis Research Center, is currently developing analytical models to describe the on-orbit cryogenic fluid transfer process. A detailed design of a Shuttie attached experimental facility, which will provide the data necessary to verify the analytical models, is also being performed by Martin Marietta.

\section{Background}

Approximately 20 years ago the Lewis Research Center (LeRC) initiated a research program intended to provide the technology base for the design and operation of fluid systems in the reduced gravity environment of space. The early emphasis of this program involved the use of small transparent tanks and the LeRC drop tower to experimentally study the behavior of liquid-vapor interfaces in response to changes in gravity level, disturbances and liquid draining from the tank. The experimental program was later expanded to include studies of liquid sloshing, settling and flow into tanks. In addition, boiling, venting, bubble motion, gas jet impingement on liquid surfaces and the use of baffles to reduce liquid residuals during outflow were examined experimentally. During the 1970s the emphas is of the LeRC program was directed toward the development of technology for the design of fluid management systems, including liquid acquisition, thermal control of cryogenic tankage and fluid transfer. 1

\section{Introduction}

In the space environment, the absence of gravity presents a significant technical problem for the transfer of cryogenic liquids. In a normal gravity earth environment tanks are normally vented as they are filled. In space, however, direct venting of gas, rather than liquid, from a tank is not straightforward. Capillary principles can be used to provide for collection of liquid, but these same principles do not serve to selectively vent gas from a tank.

This paper is declared a work of the U.S.

Government and therefore is in the public domain.
Several contractual studies have been completed which specifically addressed the problem of reduced-gravity fluid transfer with particular emphasis on systems for managing cryogenic liquids. These studies differed both in the potential applications analyzed and the proposed technique for filling tanks on-orbit and, thus, present different analytical solutions to the problem. Reference 2 analyzed a filling technique based on maintaining separation of the liquid and vapor phases within the receiver tank during the entire fill process. This technique relies on favorable orientation of the receiver tank so that the very low acceleration environment generated by atmospheric drag will position the liquid and allow direct venting from the vapor region of the tank to maintain an acceptable pressure level. An alternate concept for providing the desired acceleration environment, the use of tethers between the Space Station and a Space Vehicle Servicing Facility, is currently being studied by Mart in Marietta under NASA/JSC contract 9-17059. In general, for the. "fluid dynamic" liquid transfer technique, extremely low liquid transfer flow rates or long tethers are required in order that the stability of the liquidvapor interface is maintained.

In contrast to the above "fluid dynamic" techniques, Refs. 3 and 4 present the analysis of a "thermodynamic" technique for the on-orbit filling of receiver tanks. The thermodynamic filling technique is based on the concept of alternately chilling and venting cryogenic tankage until the receiver tank is cold enough that the tank can be filled without venting. The emphasis of the LeRC fluid management program during the past several years has been focused on the development of the Cryogenic Fluid Management Facility (CFMF) NASA/LeRC Contract 3-23355. The CFMF is a reusable, Shuttle attached test bed that can generate the data necessary to verify the "thermodynamic" filling technique analysis.

The detailed design of the CFMF is currently being aided by the development of a fluid transfer system computer code that includes analytical models of the fluid dynamic and thermodynamic processes of interest. This computer code will be used to perform cryogenic fluid transfer system parametric analysis prior to finalizing the CFMF design and experimental test plan. The objective of this paper is to present an overview of these analytical models as well as a discussion of the requirements, potential benefits and status of the LeRC on-orbit cryogenic fluid transfer technology program. 


\section{Potential Applications}

A number of future NASA and DOD missions have been identified that will require resupply of cryogens in orbit. In some instances vehicles will be boosted to orbit without fluids to minimize weight and optimize thermal performance. The cryogenic fluids will be separately transported to orbit and then must be transferred in the low-gravity environment of space. In other applications expendable cryogenic liquids will be periodically resupplied to extend the useful life of space experiments, satellites and Space Station subsystems.

Space Station auxiliary propulsion, electrical energy storage, life support and thermal control subsystems are all potential users of cryogenic liquids. In addition, the Space Station is anticipated to eventually have the capability to service satellites and Orbit Transfer Vehicles (OTV), providing both cryogenic coolants and propellants. Potential military applications also include cryogenically fueled upper stages as well as SpaceBased Laser systems which may employ cryogenic liquids as reactants, coolants and propellants.

The 0TV payload transportation requirements are anticipated to grow with the evolution of the space Station. As satellite/payload placement requirements become more demanding the on-orbit topping of ground based 0TV propellant tanks at the Space Station will become desirable to: (1) rep.lenish cryogenic propellant boil-off, and (2) overcome the 1 aunch weight restrictions associated with the Shuttie. Eventually, space-based reusable OTVs having higher energy capability will be required to meet the payload placement capability demands envisioned for the mid-1990s time frame and beyond.

\section{Benefits}

The on-orbit modular replacement of cryogenic liquid storage tanks is possible. Some advanced development would still be required to assure the availability of fluid couplings and leak detection devices suitable for use in the space environment. However, modular tank replacement appears to be reasonable only for those applications which require modest quantities of liquid due to the resulting higher storage system mass and operational complexity.

Figure 1 illustrates the impact of the availability of on-orbit cryogenic fluid transer technology as a function of storage system size. Shuttle transportable subcritical liquid oxygen storage tanks have been conceptually designed, using state-of-the-art thermal control technology, to be transported to orbit either empty or loaded with cryogenic liquid. The initially loaded tanks have a significantly higher boil-off rate on orbit due to the greater heat leak which results from the 1 arger and more numerous support struts required to transmit the higher loads during Shuttle ascent. The boil-off from the intially loaded tank exceeds that from the initially empty tank by approximately sixty percent of the initial propellant load in the first year. Consequentiy, after only 1.6 years the oxygen storage system transported to orbit empty shows an advantage, an obvious benefit for Space Station cryogenic storage systems which will be designed for operational life times of 10 to 20 years.
The space-based OTV a concept that assumes on-orbit cryogenic fluid transfer technology will be available, also benefits from relaxed structural requirements. In contrast to ground-based OTV concepts which must be designed to withstand the Shuttle multi-g launch environment fully loaded with propellants, the space-based OTV can be transported to orbit empty and be structurally designed to withstand only the relatively low thrust imposed by its own engine system. A much lighter structural design results for the space-based OTV with a corresponding one to one increase in payload placement capability. The space-based OTV will also have a lighter, more efficient thermal control system due to the fact that fewer tank support struts will be required and the insulation system needs to be designed only for the space environment. However, the resulting reduction in boil-off losses will not be large because OTV missions will typically last only a few days.

of potentially much greater impact is the projected operational cost savings associated with space-based OTV concepts. A large percentage of the anticipated operating cost for any space-based OTV concept is associated with the expense of transporting propellants to orbit. ${ }^{5}$ For groundbased vehicles, which are fully loaded with propellants prior to Shuttle ascent, the earth to orbit propellant transportation cost is the same as for any dedicated Shuttle payload. However, spacebased 0TVs are to be fueled at the Space Station from cryogenic storage tanks which can be replenished on an as-available basis. The possibility exists for propellants to be at least partially supplied to the Space Station by scavenging unused propellants from the Shuttle main propulsion system and/or transporting propellants in Shuttle mounted tanks on a spaceand weight-available basis, thus greatly reducing the cost associated with operating the space-based OTV.

\section{Fluid Transfer Analysis}

Many, if not a 11 , important processes can be characterized in terms of dimensionless parameters. As part of the conceptual design of the CFMF, 6 dimensionless parameters were identified that can be used to characterize low-gravity cryogenic liquid transfer processes. Where each process or phenomenon can be isolated from interaction with other processes, data can usually be obtained from experiments to establish values for these dimensionless parameters. When all of the dimensionless parameters that are important to the phenomenon can be kept constant between the experiment and the prototype for which the data is to be used, then the results can be applied directly. Generally, geometric relationships are held constant for experiments that are designed to characterize a particular system design. For cryogenic fluid transfer, where several distinct processes or phenomena will occur simultaneously, it may be impossible to maintain dimensional similitude between full scale systems and reduced scale experimental models.

Dimensionless analysis can still be a valuable cryogenic fluid transfer experiment design tool since some processes have distinct regimes of behavior. For example, fluid flow and convective heat transfer have distinct laminar and turbulent regimes (fig. 2). It is usually possible to extrapolate test data for which the values of the 
dimensionless parameters of importance are different between experimental model and prototype on the basis of similarity. However, it is necessary that the behavior regimes for the various processes be the same between the two for the test data to have any validity.

A means for overcoming the limitations of dimensionless analysis is the use of mathematical modeling techniques. Analytical models, in theory, can simultaneously solve all of the significant equations that describe the behavior of a system. By incorporating the known equations and the best available estimate of the unknown relationships, a model can be developed to predict the results of experimentation. By comparing analytical predictions with experimental results the analytical discrepancies can be identified and the presumed relationships can be modified to improve the analytical model. When a sufficient quantity and variety of test data has been satisfactorily used to develop the analytical model, the model can be employed to predict the performance of other similar systems and can be used to aid in the design of the full scale prototype.

The Martin Marietta developed Cryogenic Systems Analysis Model (CSAM) is now being used to aid the detailed design of the CFMF. CSAM defines cryogenic liquid storage and transfer systems by a conductor/node network. It includes a transient heat transfer network analysis, internal tank fluid thermodynamics and a heat exchanger routine which can simulate thermodynamic vent systems. Events and boundary conditions are programmable, permitting simulation of an entire mission. This comprehensive computer code, first used during the detailed design of the liquid hydrogen storage and supply system for the CFMF ${ }^{7}$ is useful in modeling many of the fluid management systems being investigated, including receiver tank chilldown and the no-vent fill during fluid transfer.

\section{Receiver Tank Chilldown}

When the tank to which cryogenic liquid is to be transferred is initially empty and warm, the first step in the procedure will be to cool the tank down to an acceptable temperature for the transfer to begin. A small quantity of liquid cryogen is admitted to the previously evacuated tank. This charge is held in the tank allowing transfer of heat from the tank to the cryogenic fluid to take place. All of the cryogenic liquid will be vaporized and the resulting warm vapor is then vented to space. This process may be repeated as necessary, depending on the initial temperature and thermal mass of the tank.

The temperature to which the tank must be pre-chilled is determined by the desired fiuid conditions that will exist at the end of the subsequent no-vent fill process. If the transfer is started with the receiver tank at too high a temperature, the final pressure will be excessive; the final temperature of the transferred liquid will also be increased yielding a lower density and a reduction in the mass of cryogenic liquid transferred to the receiver tank. Using a simple thermodynamic analysis, Fig. 3 shows the relationship between initial tank temperature, tank massto-volume ratio and the final receiver tank pressure at the end of the liquid transfer operation. The space-based OTV concept developed by the Boeing
Co. 8 has a liquid hydrogen propellant tank with a mass-to-volume ratio of approximately $0.31 \mathrm{~b} / \mathrm{ft}^{3}$; the concept presented in Ref. 9 by General Dynamics Convair has two liquid hydrogen tanks with mass-tovolume ratios of approximately $0.5 \mathrm{lb} / \mathrm{ft}^{3}$. For these very lightweight full scale oTV tanks the chilldown requirement is minimized.

For smaller scale experimental tanks there are problems in achieving such low ratios of tank mass to volume. These include minimum gages of material for manufacturing, but more importantly, higher safety factors which are necessary in order to avoid prohibitive cost and unacceptable risk. For the CFMF, it is estimated that the receiver tank mass-to-volume ratios will range from 1.5 to $2.3 \mathrm{lb} / \mathrm{ft}^{3}$, and chilldown to a temperature of $100^{\circ} \mathrm{R}$ or less will be required prior to initiating tank fill.

The CFMF receiver tank chilldown experiment illustrates the difficulty of maintaining the same value for the dimensionless groups or parameters between the experiment and full size tanks. In particular, the tank mass-to-volume ratio has been identified as one of the important parameters for this process. However, accounting for the different tank heat capacities is relatively straightforward, and the more important information to be gained from the CFMF receiver tank chilldown experiment is the characterization of the heat transfer processes.

Heat transfer will occur by three major modes. Initially, the liquid will partially vaporize as it comes into equilibrium with the reduced pressure in the tank. The remaining liquid will tend to break into drops and to spatter against the hot tank wall, being repelled by the vaporization that occurs during the brief period of contact. The drops of liquid moving through the tank will absorb heat from the vapor and will tend to vaporize as a result. Finally, vapor generated by the initial flashing of the liquid and by subsequent vaporization will exchange heat with the wall by free or forced convection or by conduction. These heat transfer processes will be governed by the fluid properties, the tank wall and fluid temperatures and the tank size. It is possible by proper modeling to account for the discrepancy in tank mass-tovolume ratio to a much greater extent than it is to determine the expected low-g heat transfer characteristics by ground testing or evaluation of available data.

Because tank size is also expected to be an important variable, two tank sizes will be used during the CFMF investigation of receiver tank chilldown. The greater mass-to-volume ratio of the experiment tanks provides two benefits. For the greater tank mass-to-volume ratio, it is desirable and probably necessary, to perform multiple charge cycles (figs. 4 and 5). In theory, less quantity of cryogen will be required if multiple charge cycles are employed because the average temperature, and thus enthalpy, of the vented fluid will be higher. The second advantage comes from the fact that the multiple charge cycle experiment will evaluate heat transfer repeatedly; each cycle with a different tank wall temperature, thus providing much more heat transfer data. 
Receiver Tank No-Vent Fill

Because of the difficulty or impossibility of directly venting gas from a tank in a low-g environment, the no-vent fill concept is the most promising approach for transfer of cryogens in space. Analysis shows that the thermodynamic processes in the receiver tank are complex and that adequate data for prediction of rates at which the transfer can be accomplished are not available.

Analysis of the thermodynamics in the receiver tank during transfer can be considered in three phases. The first phase, starting at the beginning of transfer, involves vaporization of part of the incoming liquid, or flashing. This occurs because the pressure in the tank is lower than the vapor pressure of the incoming liquid, and it partially vaporizes. During this phase, additional vaporization may occur due to excess heat contained in the tank walls and internal hardware if they have not been prechilled to liquid temperature.

Flashing of the liquid continues until the incoming liquid is in equilibrium with the tank pressure. At that point, the second phase begins. Cont inued inflow of liquid causes compression of the vapor, and the tank pressure will rise above the vapoi pressure of the incoming liquid. As the pressure irereases, vapor will begin to condense at the liquid interface, the third phase of the process. When the receiver tank pressure reaches its specified maximum operating limit, further transfer into the tank can occur only as condensation of vapor makes room for more liquid.

Condensation of vapor is the most important process in the no-vent fill procedure. The liquidvapor interfacial area available for condensation as well as the rate at which condensation occurs at the interface will limit the rate at which transfer can proceed. Whenever the liquid interface is at a temperature that is below the saturation temperature corresponding to the tank pressure, vapor will condense at the interface. However, this condensation deposits the heat of condensation into the interface layer, and quickly raises its temperature to the saturation point. Further condensation is dependent on transfer of heat from the interface into the bulk of the liquid. Consequently, to enhance this heat transfer, means for promoting mixing should be considered.

Under reduced-gravity conditions the liquidvapor interface configuration is established primarily by surface tension forces. However, the interface position and area will also be influenced by the flow of liquid into the tank. The interface area is expected to increase due to mixing induced generation of vapor bubbles within the liquid. The bubbles may not separate from the liquid or coalesce due to the lack of boyuancy. Consequently, determining the effectiveness of mixing methods and the resulting prediction of condensation rates is expected to be more difficult than would be anticipated for earth based experiments.

As the quantity of liquid transferred increases, the volume of the vapor decreases, and as the tank approaches a nearly full condition the total interfacial area, regardless of the mixing mode, decreases. Therefore, it is possible that the rate of liquid transfer will be severely reduced as the tank becomes filled to the 80 or 90 percent level. CFMF receiver tanks will have thermodynamic vent systems (TVS) available to aid in the final tank filling if required. The TVS operates by withdrawing a small amount of cryogenic liquid from the transfer system and passing it through a Joule-Thomson valve where a pressure and temperature reduction takes place. This cold twophase vent fluid is then introduced into a heat exchanger, mounted on the receiver tank wall, where evaporation continues and heat absorption takes place before the resulting vapor is vented overboard. The cold tank wall will enhance the internal condensation process and thus aid the tank filling operation.

The no-vent fill process has been analyzed, using the CSAM computer code. Percent liquid filling is plotted versus time (fig. 6) for the CFMF mission number 2 receiver tank and the Boeing concept 0TV hydrogen tank. The initial tank temperatures, $100^{\circ} \mathrm{R}$ for the CFMF and $400^{\circ} \mathrm{R}$ for the Boeing 0TV, were selected so that the final tank pressure would be the same (see fig. 3 ). Due to the higher initial temperature, the OTV tank pressure increases rapidly to near the final value. Consequently, the OTV liquid transfer operation proceeds slower than for the CFMF receiver tank because the supply tank pressure was assumed to be constant. These analytical simulations indicate that liquid transfer times of a few hours may be required for the large OTV tanks.

Developing on-orbit cryogenic fluid transfer capability is dependent on obtaining data on the no-vent fill process in space and several no-vent fill experiments will be inclided in the CFMF program. The initial liquid inflow rate will be one experimental variable and beciuse it is desirable to evaluate mixing modes, two nozzle configurations, illustrated in Fig. 7 , will be included to employ the liquid transfer flow as the source of mixing energy. A set of tangential nozzles will establish a rotational motion of the fluid within the tank providing centrifugation and a known liquid-vapor interfacial configuration. A second nozzle will be oriented axially, establishing a second flow pattern within the tank. This axial nozzle, when used in conjunction with the tangential nozzles, will tend to give a more random motion to the liquid. By comparing the rates of receiver tank filling, pressure response, and temperature changes these different mixing modes can be characterized.

\section{Experiment Design Considerations}

Early in the CFMF concept development phase several sub-scale experiment configurations were considered.6,10 A conceptual design was selected that will provide the experimental data to meet all the program tefhnical objectives at an acceptable cost to NASA. II This pallet-mounted experimental apparatus requires a one-quarter Shuttle payload bay allocation and two flights to obtain the required experimental data for on-orbit cryogenic fluid transfer technology development. (The currently planned third flight of CFMF will add to this data base, but the primary objective of the third mission is to evaluate candidate OTV fluid management concepts).

The CFMF mission 1 and 2 receiver tanks, when compared with the Ref. 9 space-based OTV concept, are 0.5 and 0.3 scale, respectively, based on an 
equivalent tank diameter. These receiver tank sizes are more than adequate to ensure similarity of the chilldown heat transfer processes between the experimental apparatus and full-scale systems. The two CFMF flights, employing the two different receiver tank sizes, will provide the data necessary to quantify the scaling relationships contained in the heat transfer equations within the complete system analytical model.

Figure 3 dramatically illustrates the point that the filling of subscale tanks will be much more difficult than for full-scale systems. However, of greater significance is the fact that the curves become essentially superimposed at initial receiver tank temperatures below $100^{\circ} \mathrm{R}$ because the heat capacity of the aluminum tanks decreases dramatically at these low temperatures. Consequently, if the receiver tanks are sufficiently prechilled, the tank mass is no longer important and the receiver tank pressure response, as a function of the tank percent filling, will be essentially identical regardless of system size. This conclusion is based on the assumption that adequate fluid mixing will be provided so that nearthermodynamic equilibrium will exist in the receiver tank during the filling operation. The CFMF design provides for different mixing techniques, as well as the use of thermodynamic vent systems, to be examined experimentally to establish preferred approaches for maintaining near thermodynamic equilibrium.

\section{Concluding Remarks}

The ultimate goal of NASA's on-orbit cryogenic fluid transfer technology development program is to provide analytical tools and design criteria for full scale systems requiring resupply of cryogenic. liquids in-space. This goal is being pursued through the development of both analytical models, which will describe fluid transfer system performance, and experimental hardware (CFMF), which can be used to obtain the data necessary to verify or modify, as required, the analytical models.

Thus far the analytical models have proven to be valuable tools, aiding the design of the CFMF. Analytical projections of CFMF and OTV liquid transfer operations are being employed to select experimental parameters such as supply tank pressure and liquid transfer rates. The effect of receiver tank mass-to-volume ratio on the cryogenic fluid transfer process has also been studied parametrically leading to the selection of an experimental plan that involves two Shuttle flights employing receiver tanks differing in size.

The selection of a suitable size for subscale experimental apparatus is often a point of controversy. From an operational point of view, the quantity of cryogenic liquid required to accomplish receiver tank chilldown will be only a few percent of the total receiver tank capacity. This fact suggests that during the early operating phases of full-scale orbital cryogenic systems requiring resupply, a conservative approach can be employed to overcome any uncertainty that might still exist in the analytical models employed during the system design. Very little cryogenic liquid loss penalty will accrue from pre-chilling the receiver tank to near the liquid temperature, prior to initiating the liquid transfer operation, with a corresponding significant increase in confidence in successfully completing the tank filling. Once some experience has been gained with the full-scale systems, the amount of conservatism employed can be relaxed.

\section{References}

1. Aydelott, J. C. and Symons, E. P., "LeRC Reduced Gravity Fluid Management Technology Program," NASA TM-81450, 1980.

2. Cady, E. C. and Miyashiro, H. H., "Filling of Orbital Fluid Management Systems, Final Report," McDonne] ]-Douglas Astronautics Co., Hunt ington Beach, CA., MDC-G-7374, Aug. 1978 (NASA CR-159405).

3. Merino, F., Blatt, M. H. and Thies, N. C., "Filling of Orbital Fluid Management Systems," General Dynamics/Convair, San Diego, CA. CASD-NAS-78-010, July 1978 (NASA CR-159404).

4. Merino, F., Risberg, J. and Hill, M., "Orbital Refill of Propulsion Vehicle Tankage," General Dynamics/Convair, San Diego, CA., GDC-CRAD-80-001, Feb. 1980 (NASA CR-159722).

5. Steinbronn, 0. and Charhut, D., "Space Station Needs, Attributes, \& Architectural 0ptions, Final Briefing Report," General Dynamics/ Convair, Fort Worth, TX., Apr. 1983 (NASA CR-173345).

6. Willen, G. S., Riemer, D. H. and Hustvedt, D. C., "Conceptual Design of an In-Space Cryogenic Fluid Management Facility, "Beech Aircraft Corp., Boulder, CO., BAC-ER-14967, Apr. 1981 (NASA CR-165279).

7. Eberhardt, R. N., Bailey, W. J. and Fester, D. A., "Cryogenic Fluid Management Experiment, Final Report," Martin Marietta Corp. Bethesda, MD., MCR-81-59T, Oct. 1981' (NASA (R-165495).

8. Davis, E. E., "Future Orbital Transfer Vehicle Technology Study," Vol. 2, NASA CR-3536, 1982.

9. "Definition of Technology Development Missions for Early Space Station; Orbit Transfer Vehicle Servicing," Vol. 2, General Dynamics/ Convair, San Diego, CA., (NASA CR-170863), June 1983.

10. Drake, G. L., Bassett, C. E., Merino, F., Siden, L. E., Bradley, R. E., Carr, E. J. and Parker, R. E., "Conceptual Design of an Orbital Propellant Transfer Experiment," Vol. 2, General Dynamics/Convair, San Diego, CA., GDC-ASP-80-013, Aug. 1980 (NASA CR-165150).

11. Eberhardt, R. N., Gille, J. P., Bailey, W. J. and Berry, R. L., "Cryogenic Fluid Management Facility Concept Definition Study, "Martin Marietta, Denver, C0., Dec. 1983 (NASA CR-174630). 


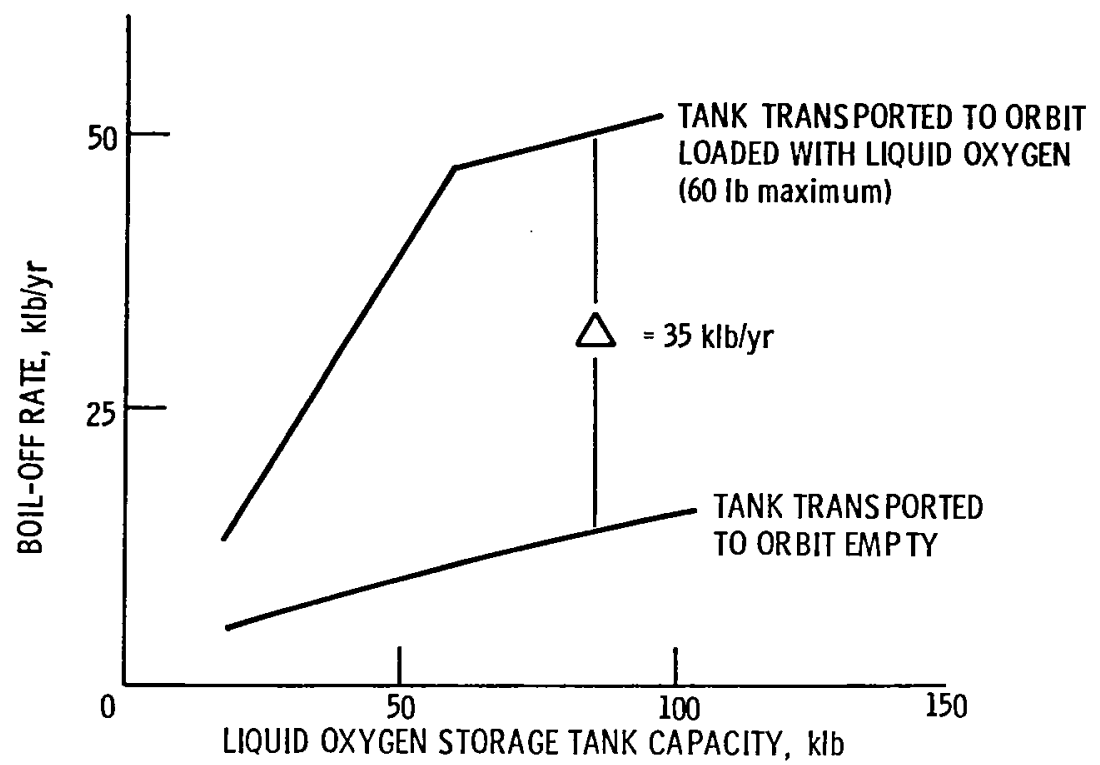

Figure 1. - Orbital liquid oxygen storage tank boil-off rates as a function of tank capacity.

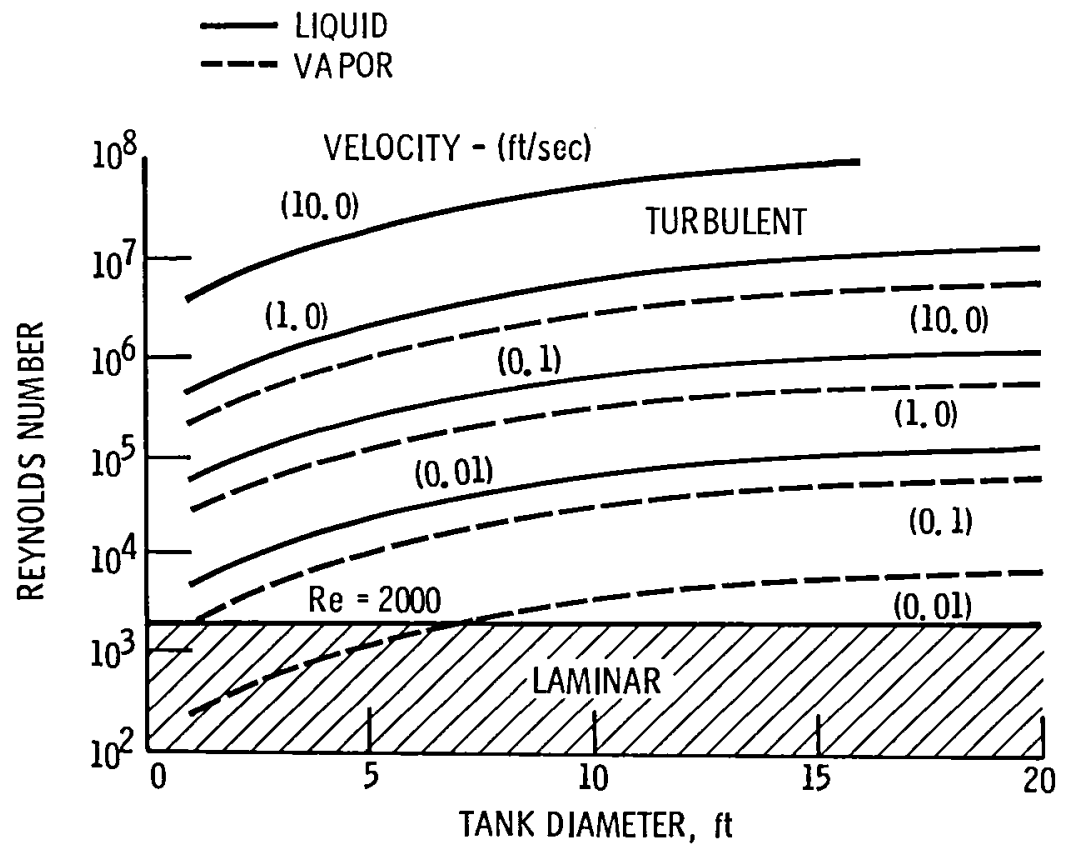

Figure 2. - Reynolds number versus tank size and fluid velocity for hydrogen. 


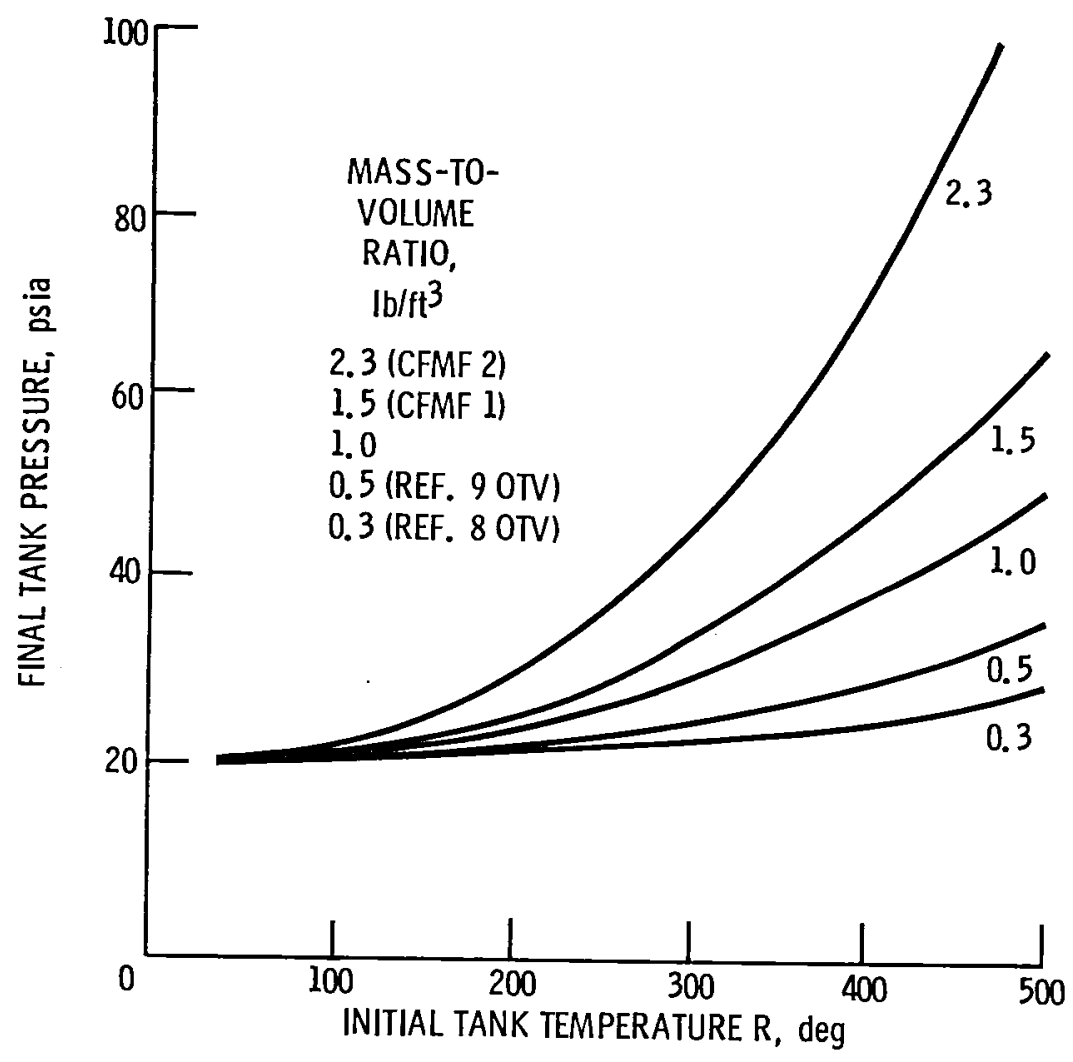

Figure 3. - Final tank pressure after no-vent fill versus tank initial temperature and mass-to-volume ratio.

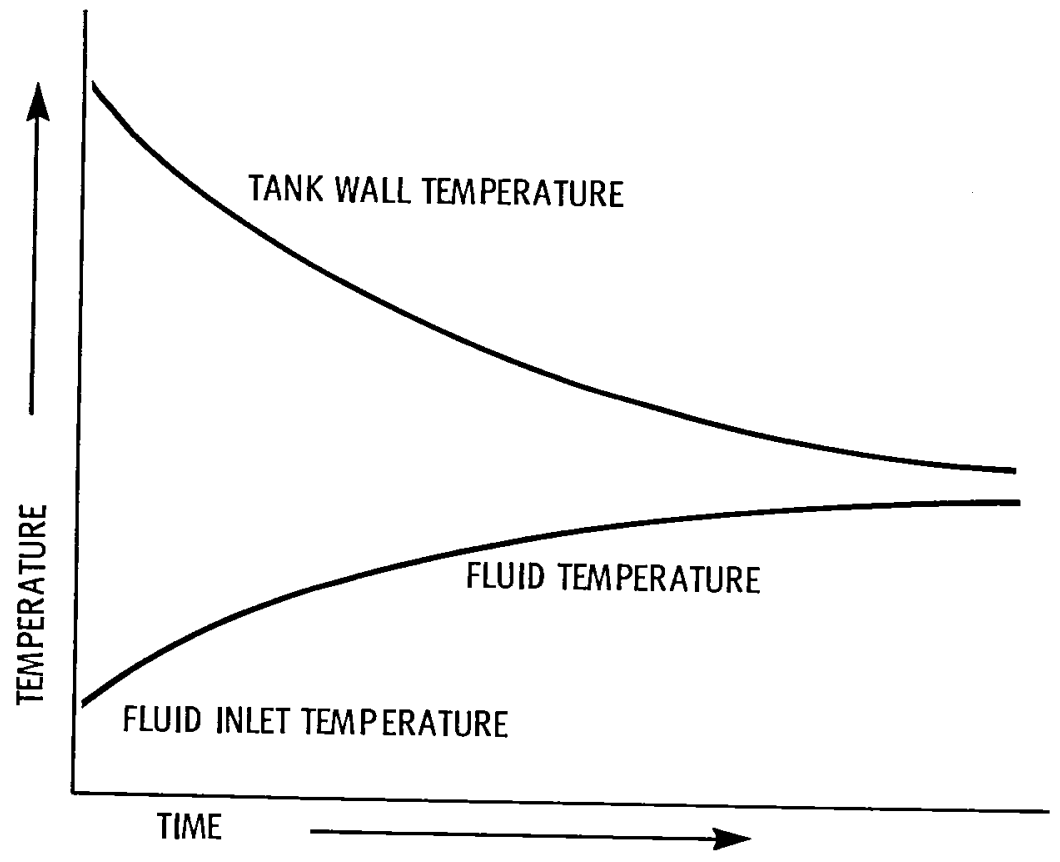

Figure 4. - Tank chill-down single charge cycle. 


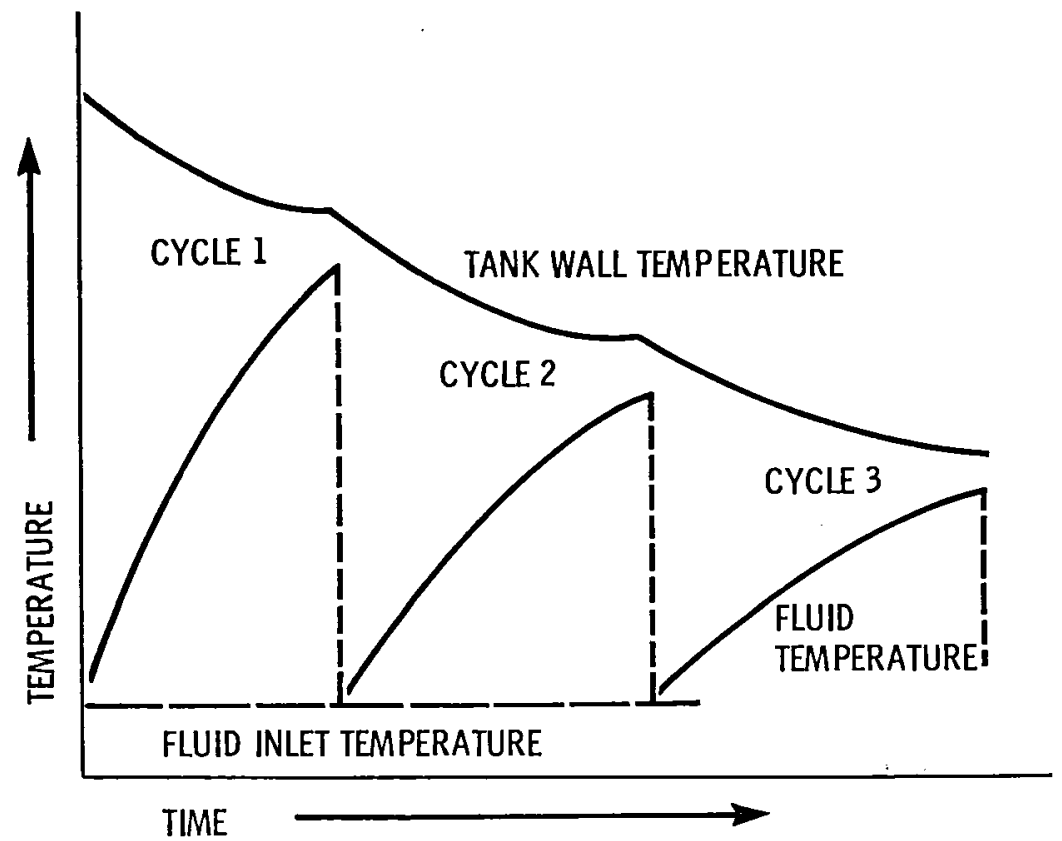

Figure 5. - Tank chill-down three charge cycles.

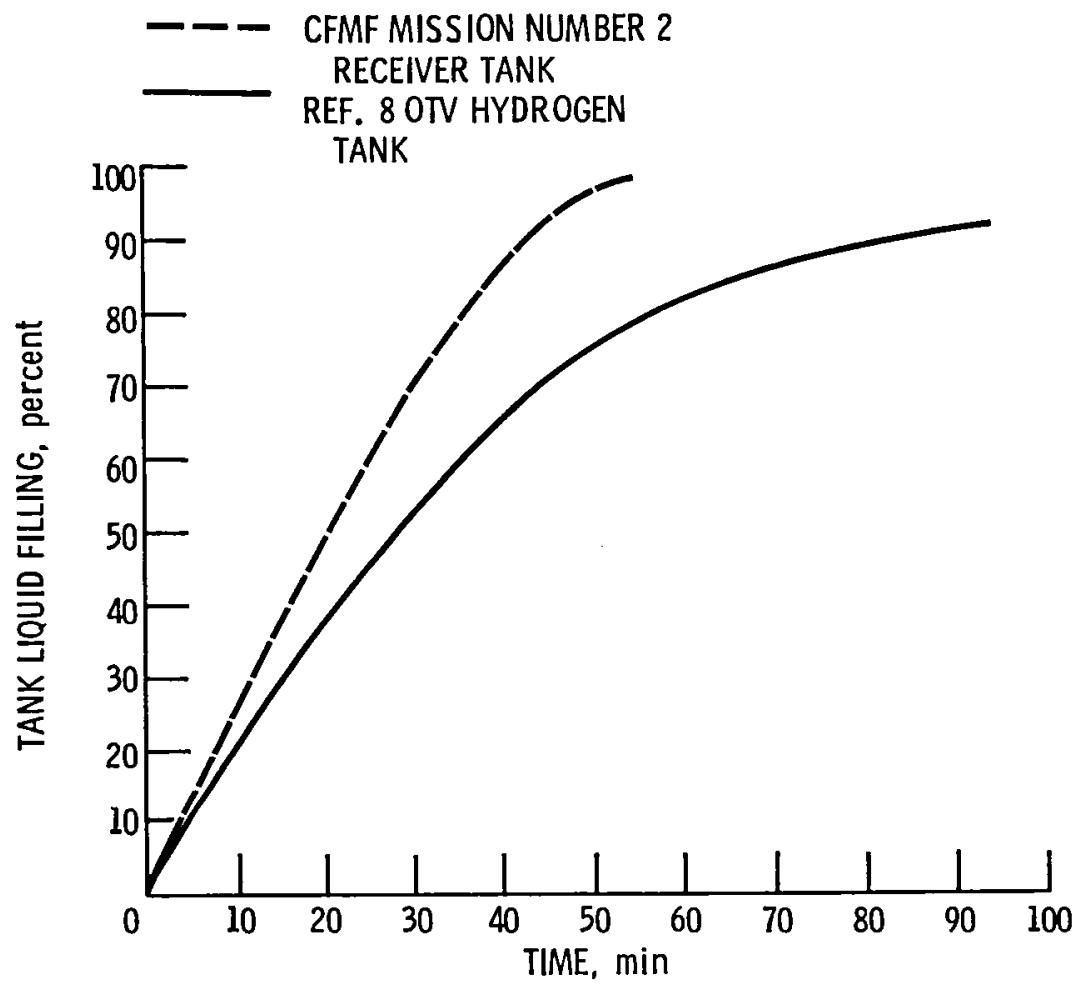

Figure 6. - Percent liquid filling versus time for CFMF AND OTV tanks. 


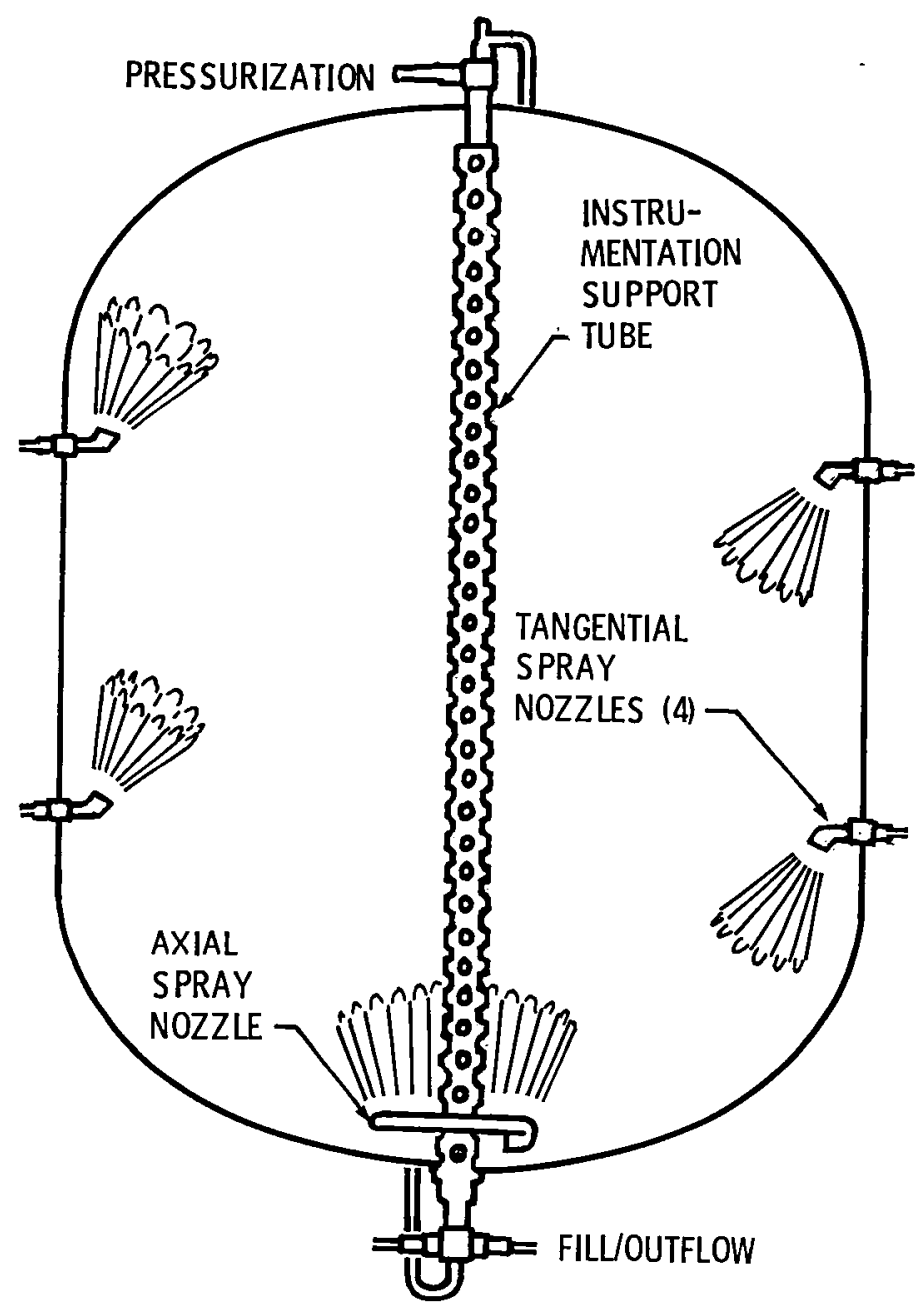

Figure 7. - CFMF receiver tank. 


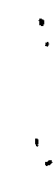




\begin{tabular}{|c|c|c|c|}
\hline $\begin{array}{l}\text { 1. Report No. NASA TM-83688 } \\
\text { AIAA-84-1343 }\end{array}$ & 2. Government Accession No. & \multicolumn{2}{|c|}{ 3. Recipient's Catalog No. } \\
\hline \multicolumn{2}{|c|}{$\begin{array}{l}\text { 4. Title and Subtitle } \\
\text { On-Orbit Cryogenic Fluid Transfer }\end{array}$} & \multicolumn{2}{|l|}{ 5. Report Date } \\
\hline \multicolumn{2}{|l|}{ 7. Author(3) } & \multicolumn{2}{|c|}{$\begin{array}{l}\text { 8. Performing Organization Report No. } \\
\text { E-2139 }\end{array}$} \\
\hline \multirow{3}{*}{\multicolumn{2}{|c|}{$\begin{array}{l}\text { 9. Pertoming Organization Name and Address } \\
\text { National Aeronautics and Space Administration } \\
\text { Lewis Research Center } \\
\text { Cleveland, Ohio } 44135\end{array}$}} & \multicolumn{2}{|l|}{ 10. Work Unit No. } \\
\hline & & \multicolumn{2}{|c|}{ 11. Contract or Grant No. } \\
\hline & & \multirow{2}{*}{\multicolumn{2}{|c|}{$\begin{array}{l}\text { 13. Type of Report and Period Covered } \\
\text { Technica } 7 \text { Memorandum }\end{array}$}} \\
\hline \multirow{2}{*}{\multicolumn{2}{|c|}{$\begin{array}{l}\text { 12. Sponsoring Agency Name and Address } \\
\text { National Aeronautics and Space Administration } \\
\text { Washington, D.C. } 20546\end{array}$}} & & \\
\hline & & \multicolumn{2}{|c|}{ 14. Sponsoring Agency Code } \\
\hline \multicolumn{4}{|c|}{$\begin{array}{l}\text { 15. Supplementary Notes } \\
\text { John C. Aydelott, NASA Lewis Reserach Center; John P. Gille and Ralph N. Eberhardt, } \\
\text { Martin Marietta Denver Aerospace, P.0. Box 179, Denver, Colorado 80201. Prepared } \\
\text { for the Twentieth Joint Propulsion Conference cosponsored by the AIAA, SAE, and } \\
\text { ASME, Cincinnati, Ohio, June 11-13, } 1984 \text {. }\end{array}$} \\
\hline \multicolumn{4}{|c|}{$\begin{array}{l}\text { 16. Abstract } \\
\text { A number of future NASA and DOD missions have been identified that will require, or } \\
\text { could benefit from resupply of cryogenic liquids in orbit. The most promising } \\
\text { approach for accomplishing cryogenic fluid transfer in the weightless environment } \\
\text { of space is to use the "thermodynamic" filling technique. This approach involves } \\
\text { initially reducing the receiver tank temperature by using several charge-hold-vent } \\
\text { cycles followed by filling of the tank without venting. Martin Marietta Denver } \\
\text { Aerospace, under contract to the NASA Lewis Research Center, is currently develop- } \\
\text { ing analytical models to describe the on-orbit cryogenic fluid transfer process. } \\
\text { A detailed design of a Shuttle attached experimental facility, which will provide } \\
\text { the data necessary to verify the analytical models, is also being performed by } \\
\text { Martin Marietta. }\end{array}$} \\
\hline $\begin{array}{l}\text { 7. Key Words (Suggested by Author(s)) } \\
\text { Space transportation } \\
\text { Liquid propellants } \\
\text { Reduced gravity } \\
\text { Fluid dynamics } \\
\text { Heat transfer }\end{array}$ & $\begin{array}{l}\text { 18. Dis } \\
\text { Un } \\
\text { ST }\end{array}$ & $\begin{array}{l}\text { dent }- \text { unlimited } \\
\text { ry } 16\end{array}$ & \\
\hline $\begin{array}{l}\text { 9. Security Classif. (of this report) } \\
\text { Unclassified }\end{array}$ & $\begin{array}{l}\text { Security Classif. (of this page) } \\
\text { Unclassi fied }\end{array}$ & 21. No. of pages & 22. Price \\
\hline
\end{tabular}

*For sale by the National Technical Information Service, Springfield, Virginia 22161 


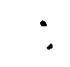

:

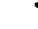


National Aeronautics and Space Administration

Washington, D.C.

20546

Official Business

Penalty for Private Use. $\$ 300$
SPECIAL FOUATH CLASSMAIL BOOK

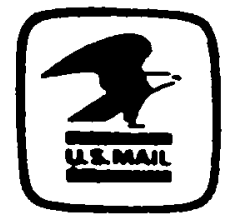

Postege and Foes Paid Netional Aeronoutics and Spece Administration NASA-451 